\title{
QUADRO DE PROBLEMAS DE POLÍTICAS PÚBLICAS: UMA FERRAMENTA PARA ANÁLISE JURÍDICO-INSTITUCIONAL ${ }^{1}$
}

\section{PUBLIC POLICIES PROBLEMS FRAMEWORK: A TOOL FOR LEGAL-INSTITUTIONAL ANALYSIS}

\author{
ISABELA RUIZ ${ }^{2}$ \\ MARIA PAULA DALLARI BUCCI ${ }^{3}$
}

RESUMO: Este artigo tem como objetivo apresentar uma proposta de método para identificar e descrever problemas de políticas públicas. Partindo da abordagem Direito e Políticas Públicas (DPP), que procura compreender a estruturação jurídica dos programas de ação governamental em seu contexto políticoinstitucional, e considerando que há limitações do Quadro de Referência de uma Política Pública (BUCCI, 2015) para a análise de programas não estruturados ou em processo de estruturação, este artigo propõe uma ferramenta complementar de sistematização de informações para análises jurídico-institucionais de situações-problema relativas aos programas de ação governamental. O método proposto sugere meios para a identificação dos grupos de interesse, processos decisórios e instituições implicadas no objeto de análise, com o fim de identificar e delimitar os aspectos mais relevantes e característicos para o estudo jurídico de um problema público, visando à ação prospectiva.

Palavras-Chave: Políticas públicas; Método; Análise jurídico-institucional.

\footnotetext{
${ }^{1}$ Agradecemos aos membros do grupo de pesquisa Estado, direito e políticas públicas pela leitura atenta da versão preliminar deste artigo, em especial a Carolina Gabas Stuchi (UFABC), Clarice Seixas Duarte (Universidade Presbiteriana Mackenzie), Ester Gammardella Rizzi (EACH-USP), Luiz Gustavo Bambini de Assis (EACH-USP), Fernanda Vick Soares de Sena e Matheus Silveira de Souza pelos comentários e sugestões que contribuíram para o aprimoramento deste trabalho.

2 Mestranda em Direito do Estado pela Faculdade de Direito da Universidade de São Paulo FDUSP (Brasil). Contato: isabelaruiz@usp.br. Lattes: http://lattes.cnpq.br/3595284581976778.

${ }^{3}$ Professora Associada da Faculdade de Direito da Universidade de São Paulo - FDUSP (Brasil). Contato: mariapaula@usp.br. Lattes: http://lattes.cnpq.br/5277262878389044.
} 
ABSTRACT: This paper aims to present a method proposal to identify and describe public policies problems. Starting from the Law and Public Policy (LPP) approach, which seeks to understand the legal structuring of governmental action programs in their political-institutional context, and considering that there are limitations of the Reference Framework of a Public Policy (BUCCI, 2015), for the analysis of non-structured programs or programs in process of structuring, this article proposes a complementary tool for systematizing information for a legalinstitutional analysis of problem-situations related to governmental action programs. The proposed method suggests means for identification of interest groups, decision-making processes and institutions that are involved in the object of analysis, in order to identify and delimit the most relevant and distinctive aspects for the legal study of a public problem, aiming to prospective action.

KEYWORDS: Public policies; Method; Legal-institutional analysis.

\section{INTRODUÇÃO}

O presente artigo tem o objetivo de apresentar e testar uma proposta de ferramenta metodológica para identificar e descrever problemas de políticas públicas, ou seja, situações que dizem respeito a um determinado problema público, entendido coletivamente como relevante para ser tratado ou resolvido por meio de um programa de ação governamental ${ }^{5}$.

A ferramenta foi concebida como contribuição ao campo de pesquisa multidisciplinar ${ }^{6}$ que realiza análise de políticas públicas, com foco nos pesquisadores que buscam ferramentas para compreender os aspectos jurídicoinstitucionais dessas políticas.

Para empreender esse tipo de análise, tem-se recorrido ao que se convencionou denominar de abordagem Direito e Políticas Públicas (DPP ${ }^{7}$ ),

\footnotetext{
${ }^{4}$ Utilizamos aqui a noção de problema público para identificar uma situação que é considerada inadequada por uma coletividade de atores políticos, passível de ser tratada ou resolvida pela ação do poder público, que tenha implicações para uma quantidade ou qualidade notável de pessoas, na expectativa de se alcançar uma situação melhor (SECCHI, 2012).

5 A locução ação governamental é utilizada neste artigo como sinônimo de política pública, pois adotamos aqui o conceito de política pública como um "programa de ação governamental que resulta de um conjunto de processos juridicamente regulados, visando coordenar os meios à disposição do Estado e as atividades privadas, para a realização de objetivos socialmente relevantes e politicamente determinados" (BUCCI, 2006, p. 39).

${ }^{6}$ Adotamos aqui o termo multidisciplinar em conformidade à qualificação do campo de análise de políticas públicas utilizada por Eduardo Marques e Carlos Aurélio Pimenta de Faria (2013).

${ }^{7}$ Para uma discussão sobre o método e as aplicações da abordagem DPP, ver Bucci (2019).
} 
campo de análise que procura compreender a estruturação jurídica dos programas de ação governamental em seu contexto político-institucional.

Uma das ferramentas metodológicas à disposição dos pesquisadores para uma compreensão do papel do Direito na conformação, estruturação e implementação das políticas públicas é o Quadro de Referência de uma PolíticaPública (BUCCI, 2015), concebido como instrumento de apoio didático para pesquisa.

O Quadro de Referência permite o isolamento do objeto de estudo mediante uma leitura sistemática das normas que constituem uma política pública, viabilizando ao pesquisador destacar o objeto de análise do conjunto de atos normativos, decisões executivas e medidas operacionais que o conformam, pela identificação de elementos que lhe são específicos e diferenciando-o de normas que o sustentam, mas não são exclusivas daquele programa (BUCCI, 2015).

Essa ferramenta tem sido amplamente utilizada e tem se mostrado bastante apropriada para auxiliar pesquisadores a descrever políticas públicas já estruturadas e institucionalizadas. No entanto, seu uso tem se revelado limitado para a análise de programas não estruturados ou em processo de estruturação, visto que, nessas situações, não é possível identificar todos os elementos do Quadro e a visualização do problema resulta incompleta.

Assim, esse artigo apresenta uma proposta de método, que aspira incitar uma discussão sobre o preenchimento dessa lacuna no espectro metodológico da abordagem Direito e Políticas Públicas, propondo uma ferramenta complementar de sistematização de informações, voltada especificamente para análises jurídicoinstitucionais de situações-problema relativas aos programas de ação governamental.

O método aqui apresentado, que designaremos como Quadro de Problemas de Políticas Públicas, foi desenvolvido com base em modelos já consagrados de análise de políticas públicas, como o ciclo de formação de políticas públicas (que simplifica o processo de criação e implementação de uma política, com grande foco no momento de tomada de decisão governamental), o modelo das múltiplas correntes, de Kingdon (1995) (que identifica variáveis importantes no fluxo do processo que antecede o momento de tomada de decisão acerca da política) e a perspectiva teórica que problematiza a não-tomada de decisão (BACHRACH; BARATZ, 1963; 2011).

Os modelos teóricos acima identificados, que embasam o presente trabalho, foram selecionados pela centralidade que conferem ao tema da tomada de decisão governamental. Esse é o elemento central para as análises jurídico-institucionais que privilegiam a institucionalidade jurídica, isto é, as normas, atos e processos que dão corpo às decisões e suas conexões com os agentes nas arenas de disputa política. E é justamente a ausência (ou não-tomada) de determinadas decisões, que implica na escassez de normas que estruturem a ação governamental, o que caracteriza, muitas vezes, os problemas de políticas públicas - para a análise dos quais se direciona a ferramenta aqui proposta. 
O presente artigo está organizado em três seções, para além desta introdução e das considerações finais. Na primeira seção, fundamenta-se a referência teórica adotada para o método aqui proposto. Na segunda, são descritos os elementos que compõem o Quadro de Problemas de Políticas Públicas, cujo intuito é viabilizar a identificação e o isolamento de uma situação-problema em seu aspecto jurídico-institucional. E na terceira, empreende-se uma verificação prática da ferramenta proposta, com a aplicação do método para a descrição do problema do hiperencarceramento no Brasil.

\section{Pressupostos TeÓRICOS E MetOdOLÓGICOS}

A perspectiva jurídico-institucional busca iluminar o aspecto normativo de um problema público. Procura colocar o Direito como elemento fundamental para a análise de políticas públicas, conferindo destaque às normas que estruturam as instituições, que estabelecem os procedimentos e determinam as competências dos agentes envolvidos no processo de formulação, implementação e avaliação dos programas de ação governamental.

Para fundamentar a ferramenta de análise jurídico-institucional proposta nesse artigo, partimos, inicialmente, da abordagem Direito e Políticas Públicas (DPP), que procura compreender a moldura jurídico-institucional que estrutura um programa de ação governamental, levando em consideração o contexto político-institucional no qual ela se insere (BUCCI; COUTINHO, 2017, p. 315).

A abordagem DPP incorpora os juristas ao campo multidisciplinar de estudos das políticas públicas, na medida em que seu viés analítico se volta para a base normativa que determina os procedimentos e rotinas que conformam a ação governamental. Essa abordagem permite ao pesquisador compreender o papel do componente jurídico na concepção, implementação e funcionamento dos arranjos institucionais que organizam a ação governamental em função de objetivos politicamente determinados.

A análise jurídica de políticas públicas, a partir da abordagem mencionada, permite ao pesquisador identificar os objetivos que devem ser perseguidos pela política, os instrumentos a serem utilizados para alcançá-los, os canais de participação social e legitimação democrática e seus arranjos institucionais, que dizem respeito aos modos de articulação e interação de agentes, ao grau de descentralização, autonomia e coordenação federativa e intersetorial, aos tipos de relações públicas e público-privadas, e sua integração com outros programas, a partir das normas - que são a substância de que são feitas, cotidianamente, as políticas públicas (BUCCI; COUTINHO, 2017, p. 317).

Essa noção de arranjo jurídico-institucional é bastante funcional na abordagem DPP (e, particularmente, para os fins deste artigo), pois permite uma análise integrada de inúmeros aspectos e dimensões jurídicas do objeto de estudo, o que viabiliza a compreensão da dinâmica que envolve a ação governamental, 
agregando, com um sentido sistemático, o conjunto complexo de normas, agentes, processos e instituições jurídicas que envolvem uma política pública (BUCCI; COUTINHO, 2017, p. 315).

Mas para que essa análise sistemática seja possível, é necessário, em princípio, isolar o objeto - ou seja, os aspectos exclusivamente jurídicos da ação governamental que se busca analisar. A identificação dos elementos que compõem o arranjo jurídico-institucional de uma política pública não é uma operação elementar, pois ao tentar recortar o programa de ação governamental que será analisado, o pesquisador se depara com a dificuldade de distinguir os atos normativos que o conformam, num conjunto de regras jurídicas que não são, necessariamente, exclusivas de determinado programa.

Sendo assim, muitos pesquisadores ${ }^{8}$ têm recorrido a um método estruturado, denominado Quadro de Referência de uma Política Pública (BUCCI, 2015), que permite o isolamento do objeto de análise de seu emaranhado normativo. A ferramenta viabiliza o desmembramento da política e a identificação de seus elementos mais importantes, possibilitando uma visão mais racional e organizada sobre o objeto de estudos.

O quadro reproduzido abaixo é uma forma adaptada de apresentação desse método, cujo uso já está consolidado para os analistas que utilizam a abordagem Direito e Políticas Públicas:

\section{Elemento}

Descrição

1) Nome oficial do Marca política do programa, identificação políticoprograma de ação partidária.

2) Gestão governamental Gestão que criou o programa; permite compreender seu sentido considerando o espectro políticopartidário.

3) Base normativa

Norma principal que institui o programa; disposições específicas mais importantes. Confere caráter sistemático ao programa, articulando seus elementos, em especial, os vários focos de competência dos quais depende $\mathrm{o}$ seu funcionamento. Pode ser de hierarquia variada, em geral lei ordinária ou decreto, embora possa ser também inferior ou superior.

Em complemento, a base normativa se compõe de outras normas não exclusivas do programa, nas quais se apoia o seu funcionamento.

4) Desenho jurídico- Organização do programa, numa visão macro.

8 Nesse dossiê, o artigo de Marcelo Chilvarquer é ilustrativo da utilização do Quadro de Referência aqui mencionado. 


\begin{tabular}{|c|c|}
\hline institucional & $\begin{array}{l}\text { Descreve em termos gerais seu núcleo de sentido e } \\
\text { os papéis institucionais dos principais entes } \\
\text { responsáveis pela sua implementação. }\end{array}$ \\
\hline $\begin{array}{l}\text { 5) Agentes } \\
\text { governamentais }\end{array}$ & $\begin{array}{l}\text { Identifica, a partir da base normativa, as } \\
\text { competências, atribuições e responsabilidades } \\
\text { reservadas a cada agente governamental, tanto os } \\
\text { principais, como os secundários, isto é, aqueles que } \\
\text { administrarão efeitos da conduta dos primeiros. }\end{array}$ \\
\hline $\begin{array}{l}\text { 6) Agentes } \\
\text { governamentais }\end{array}$ & $\begin{array}{l}\text { Identifica os agentes situados fora do aparelho } \\
\text { governamental que executam aspectos da política, } \\
\text { em geral mediante financiamento ou indução de } \\
\text { comportamentos. }\end{array}$ \\
\hline $\begin{array}{l}\text { 7) Mecanismos jurídicos } \\
\text { de articulação }\end{array}$ & $\begin{array}{l}\text { Modos pelos quais a ação dos vários agentes se } \\
\text { interrelaciona, apoiada em mecanismos jurídicos, } \\
\text { de gestão e de informação. }\end{array}$ \\
\hline 8) Escala e público-alvo & $\begin{array}{l}\text { Magnitude pretendida pelo programa, indicada por } \\
\text { dados quantitativos sobre beneficiários (diretos e } \\
\text { indiretos), disponíveis em bancos de dados oficiais. } \\
\text { A compreensão das ordens de grandeza recomenda } \\
\text { a comparação com programas que possam servir de } \\
\text { referência, tais como os de outros países e regiões } \\
\text { ou programas mais antigos. }\end{array}$ \\
\hline $\begin{array}{l}\text { 9) Dimensão econômico- } \\
\text { financeira do programa }\end{array}$ & $\begin{array}{l}\text { Recursos financeiros vinculados ao programa, } \\
\text { alocação orçamentária, que pode se dar na forma de } \\
\text { investimento, custeio ou pessoal. A última, em } \\
\text { regra, não é exclusiva do programa, pois os } \\
\text { servidores públicos podem atender a diversos } \\
\text { serviços e programas. }\end{array}$ \\
\hline $\begin{array}{l}\text { 10) Estratégia } \\
\text { implantação }\end{array}$ & $\begin{array}{l}\text { Movimento pretendido pelo gestor público que } \\
\text { institui o programa. } \\
\text { Combinam-se aqui o planejamento, a capacidade de } \\
\text { comunicação e a legitimação do programa, levando } \\
\text { em conta não apenas as condutas dos agentes } \\
\text { governamentais, mas as reações esperadas dos } \\
\text { demais agentes, especialmente os antagonistas do } \\
\text { programa. } \\
\text { Quando se trata de uma transformação } \\
\text { significativa, o direito tem um grande potencial de } \\
\text { conformar o processo de transição, ao definir a } \\
\text { situação das relações jurídicas em curso, o direito } \\
\text { intertemporal. }\end{array}$ \\
\hline
\end{tabular}



11) Funcionamento Compreendido o desenho ideal do programa (itens efetivo do programa 4 a 10), poderá o analista confrontá-lo com o seu funcionamento real. É importante basear-se em fontes diversas da governamental, para uma visão crítica.

12) Aspectos críticos do Análise em detalhe dos elementos jurídicos na desenho institucional jurídicoestruturação da política, capazes de explicar, pelo menos em parte, as dificuldades de sua implementação.

Como é possível observar na apresentação dos elementos acima descritos, o Quadro possibilita ao pesquisador identificar como se dá a organização do programa de ação governamental (ou seja, quais são e como se relacionam os elementos da política), quais os papéis institucionais de cada agente e qual o movimento, no sentido político e social, da agregação de interesses para atingir a finalidade pretendida pela política pública (BUCCI, 2015), permitindo ao estudioso combinar, de forma analítica, o elemento jurídico e o elemento político.

O Quadro de Referência tem sido bastante útil para pesquisas e estudos que procuram descrever políticas públicas já estruturadas, nas quais é possível ao pesquisador identificar todos os elementos ali destacados. Mas ainda que essa ferramenta permita ao analista identificar os aspectos críticos do desenho jurídicoinstitucional, seu uso se revela insuficiente para a descrição de problemas relacionados à ação governamental, ou seja, situações em que os programas não estão suficientemente estruturados, ou porque se encontram em processo de estruturação ou porque sequer entraram na agenda política.

O Quadro de Referência pressupõe (como é possível identificar na descrição do elemento 12, reproduzida acima) que a política já possua um desenho regulamentado e que já tenha sido implementada, de modo que o pesquisador possa confrontar o projeto idealizado pelos formuladores com seu funcionamento efetivo, a fim de detectar elementos jurídicos que sejam capazes de explicar aspectos problemáticos da execução. Mas no caso de situações-problema relacionadas a políticas pouco estruturadas, esse elemento do Quadro não facilita o trabalho do analista, resultando prejudicada a visualização de seu objeto de estudos.

Quando o pesquisador se depara com um problema público, ou seja, uma circunstância complexa, que exige uma ação governamental em escala (que tenha implicações para uma quantidade relativamente grande de indivíduos de uma determinada população) e identifica que o programa de ação governamental para a solução desse problema ainda não se encontra totalmente estruturado, em virtude da ausência de normas que regulem a atuação do poder público no tratamento da situação, revela-se uma grande dificuldade metodológica para a análise jurídico-institucional desse problema de política pública. 
É para essas circunstâncias que o presente artigo se destina, ao propor e descrever uma ferramenta complementar de sistematização de informações, um framework (OSTROM, 2007, p. 259), que visa identificar um conjunto de variáveis (e algumas relações entre elas) capazes de viabilizar uma análise jurídicoinstitucional de situações-problema que deveriam ensejar programas de ação governamental, os quais, todavia, ainda não estão estruturados ou o estão de maneira insuficiente.

Esse framework, que designaremos como Quadro de Problemas de Políticas Públicas, procura dar destaque ao Direito, evidenciando o lugar do elemento jurídico na análise de soluções hipotéticas, no campo das políticas públicas, para o problema descrito.

A ferramenta toma como referência o ciclo de políticas públicas (ou heurística das fases), o esquema de representação mais conhecido no campo, que organiza o processo de elaboração de uma política pública em fases sequenciais e interdependentes, quais sejam: 1) identificação do problema; 2) formação da agenda; 3) formulação de alternativas; 4) tomada de decisão; 5) implementação; 6) avaliação e 7) extinção (SECCHI, 2012, p. 33-60).

O ciclo de formação de políticas públicas pressupõe um encadeamento lógico de ações, no qual "os problemas são formulados conceitualmente e trazidos para o governo para soluções; as instituições governamentais formulam alternativas e selecionam soluções; e essas soluções são implementadas, avaliadas e revisadas" (SABATIER, 2007, p. 03). Trata-se de uma concepção que dá grande centralidade para a tomada de decisão e para suas consequências na implementação das políticas públicas.

Esse modelo foi criticado por sua abordagem legalista (SABATIER, 2007, p. 07), focada na suposição de que há um único ciclo político, centrado na aprovação e implementação de um texto de lei (BUCCI; COUTINHO, 2017, p. 319-320). Mas é justamente o conteúdo dessa crítica que nos faz considerar a importância dessa abordagem para o método de análise aqui proposto, uma vez que o componente jurídico aí se destaca, como elemento de materialidade da decisão, na medida em que lhe atribui o "selo de estatalidade" (MORAND, 1999), além de documentar formalmente as escolhas políticas e decisões do gestor político ou executor administrativo da política pública (BUCCI; COUTINHO, 2017, p. 318).

Isso porque os instrumentos normativos (leis, decretos, portarias, resoluções), uma vez aprovados em suas respectivas arenas de discussão, em observância a procedimentos juridicamente regulados, consolidam decisões importantes e impõem aos agentes governamentais e não-governamentais envolvidos no planejamento e execução da política ônus, deveres e obrigações que representam o resultado de um conflito político cuja solução fica cristalizada em determinado estágio com a culminação do processo de aprovação da norma ou ato jurídico. E a

${ }^{9}$ Ver Bucci (2019). 
decisão, materializada pela norma posta, implica na consolidação das regras e parâmetros para o funcionamento da política pública.

O Direito, nesse sentido, se revela como um elemento crucial para a análise de políticas públicas, na medida em que cria arenas, atribui competências, regulamenta o funcionamento do espaço decisório, regula as condutas dos agentes e os processos de tomada de decisão - determinando a forma da estrutura institucional no interior da qual são tomadas as decisões acerca de uma política pública - sem determinar, no entanto, o conteúdo das decisões (o que pertence ao campo da política).

Sendo assim, ao considerarmos a importância do processo de tomada de decisão, materializada pela norma ou ato jurídico, para a análise jurídicoinstitucional de uma política pública, não podemos menosprezar a relevância da perspectiva teórica que diz respeito, justamente, à não-tomada de decisão (BACHRACH; BARATZ, 1963; 2011). Esse fenômeno ocorre quando algumas pessoas ou grupos conseguem limitar a tomada de decisões a matérias relativamente não controversas, não obstante haver, na comunidade, uma questão latente que demande uma decisão política relevante.

A atuação de indivíduos ou associações a favor da exploração de alguns tipos de conflito em detrimento de outros, suprimindo determinadas questões do processo decisório, e limitando o escopo da efetiva tomada de decisões a temas relativamente "seguros", é denominada de mobilização de viés (BACHRACH; BARATZ, 2011, p. 151). Ao analisar a mobilização de viés, o pesquisador é capaz de identificar em que medida e de que maneira os valores dominantes na comunidade, os procedimentos e rituais políticos e as regras do jogo estabelecidas tendem a favorecer os interesses organizados de um ou de mais grupos, relativamente a outros grupos. E, a partir dessa análise, verificar quais pessoas ou grupos (se algum) ganham com o viés existente e quais (se algum) são prejudicados por ele (BACHRACH; BARATZ, 2011, p. 156).

Nessas situações, em que as relações de poder existentes entre os grupos e os instrumentos de força, isoladamente ou combinados, efetivamente impedem que certas queixas se transformem em questões de pleno direito que demandam decisões, mantendo-as submersas e excluídas da agenda decisória, pode-se dizer que estamos diante de uma não-tomada de decisão (BACHRACH; BARATZ, 1963, p. 641) - fenômeno distinguível dos aspectos negativos da tomada de decisão (que implicam em decidir não agir ou decidir não decidir).

Essa abordagem, que procura identificar a maneira pela qual alguns grupos de interesse e instituições políticas se tornam capazes de limitar a tomada de decisões em determinadas situações, e a respeito de determinadas matérias, é bastante relevante para o método aqui proposto, pois o pesquisador que se debruça sobre um problema de política pública pode se deparar com uma situação de inexistência de normas jurídicas, justamente pela não-tomada de decisão sobre determinada questão (ainda que latente no contexto político, econômico ou 
social de determinada comunidade). Essa é uma situação típica em que o Quadro de Referência (BUCCI, 2015) se revela limitado para auxiliar o trabalho do pesquisador.

Isso porque, para que seja possível efetuar uma análise jurídico-institucional de uma política pública, é preciso levar em conta a decisão tomada, materializada na norma posta, que viabiliza a organização da ação governamental para o enfrentamento do problema público.

E para compreensão do processo político que antecede o momento da inclusão de determinado problema na agenda decisória governamental ${ }^{10}$, o modelo de análise das múltiplas correntes (multiple streams framework) revela-se uma perspectiva teórica interessante para o método aqui proposto, pois esse modelo descreve o processo político como uma composição entre três correntes (ou fluxos) de atores e processos: a corrente dos problemas (problem stream), a corrente das soluções ${ }^{11}$ (policy stream) e a corrente da política (politics stream) (KINGDON, 1995).

A corrente dos problemas (problem stream) consiste no reconhecimento de uma questão como relevante para integrar a agenda decisória governamental. $\mathrm{O}$ reconhecimento de uma determinada situação como um problema pode se dar: i) em virtude de uma crise, um desastre ou uma situação dramática; ii) por meio de indicadores que revelem a magnitude de um determinado evento; ou iii) pelo feedback no monitoramento e avaliação de programas já existentes. Nesse fluxo (corrente dos problemas), os empreendedores de políticas (policy entrepreneurs, que são agentes que representam determinado grupo de interesse) investem recursos para convencer as autoridades de sua concepção sobre os problemas uma vez que quando uma situação passa a ser definida pelas autoridades como um problema, aumentam as chances de que ela se torne uma prioridade na agenda decisória.

A corrente das soluções (policy stream), por sua vez, envolve a formulação de propostas de solução para determinados problemas. Essas soluções representam os saberes, as inovações de ordem técnica e as tecnologias de organização do Estado que orientam a produção e a implementação da política (MARQUES, 2013, p. 40). As soluções para os problemas são geralmente formuladas e propostas por especialistas (acadêmicos, pesquisadores, burocratas), e essas propostas são apreciadas e selecionadas por critérios de viabilidade técnica, restrições orçamentárias e aceitabilidade pública e política, de acordo com o momento e o contexto em que se dá o processo. Os empreendedores de políticas buscam, nesse

10 Segundo Kingdon (1995), a agenda governamental abrange a lista de todos os assuntos que recebem atenção dos atores governamentais e a agenda decisória diz respeito aos temas dentro da agenda governamental que se tornam, efetivamente, alvo de deliberação (p. 4).

${ }^{11}$ Adotamos aqui a tradução de policy stream como "corrente das soluções", em consonância com Eduardo Marques (2013) e Leonardo Secchi (2012). 
fluxo, promover um amaciamento ${ }^{12}$ do sistema, divulgando sistematicamente e defendendo, nos espaços de discussão política, as propostas de soluções que mais se coadunam com seus interesses.

Já a corrente da política (politics stream), diz respeito à ação dos atores ${ }^{13}$, os conflitos, alianças e negociações típicas da arena política (MARQUES, 2013, p. 40) e envolve as campanhas eleitorais, candidatos e lobbies. As mudanças no cenário político (promovidas por eleições, por novos governos, ou por novas configurações partidárias ou ideológicas) podem trazer novos atores ao poder, e permitir ou inibir a atuação dos movimentos organizados da sociedade. Os empreendedores também podem agir nesse fluxo, especialmente por meio de estratégias de lobby ${ }^{14}$.

O modelo considera que essas três correntes operam de maneira relativamente independente umas das outras. E que não basta o reconhecimento de uma situação como problema pelas autoridades, nem a existência de uma solução para que um problema seja inserido na agenda, transformando-se numa política pública: é necessária a existência de um contexto político favorável no qual o problema seja reconhecido, ao mesmo tempo em que existam soluções viáveis.

Quando há conjunção dos três fluxos (problems, policies e politics) abre-se uma janela de oportunidade (window of opportunity) que aumenta significativamente as chances de que uma questão vá para a agenda de decisão. E é na convergência dos diferentes fluxos que é possível explicar o motivo pelo qual alguns temas são priorizados nas agendas governamentais, enquanto outros são negligenciados (KINGDON, 1995, p. 225).

Embora o alinhamento das janelas de cada fluxo possa ocorrer por acaso, na maior parte das vezes isso acontece pela ação concreta dos atores (MARQUES, 2013, p. 40). O acoplamento (coupling) dos três fluxos depende substancialmente da atuação dos empreendedores da política (policy entrepreneurs), que são os agentes que se dedicam a atuar no processo político, em cada um desses fluxos, alocando recursos, disponibilizando informações e utilizando estratégias de convencimento para persuadir as autoridades sobre a relevância de suas posições, buscando abrir janelas e fazer com que as decisões sejam tomadas no sentido da defesa de seus interesses, seja construindo o reconhecimento de uma questão social como um problema, incentivando a adoção de determinada solução ou

${ }_{12}$ No original, Kingdon $(1995$, p. 201) utiliza a expressão softening up. A tradução aqui utilizada é de Paulo César Nascimento, em Saravia e Ferrarezi (2006).

${ }^{13} \mathrm{O}$ termo "ator" é comumente utilizado nos estudos e análises de políticas públicas para designar agentes públicos e privados, individuais e coletivos, que atuam, influenciam ou são afetados, direta ou indiretamente, pelas políticas públicas.

${ }^{14} \mathrm{O}$ lobby diz respeito à defesa de todos os tipos de interesse diante das mais diversas formas de decisão do poder público. O lobby ocorre quando agentes sociais tomam a iniciativa de contatar membros do poder público, capazes de tomar decisões, a fim de apresentar-lhes seus interesses e pleitos (MANCUSO; GOZETTO, 2018). 
promovendo acordos e alianças políticas, bem como atuando para o alinhamento de todos esses elementos (MARQUES, 2013).

O modelo de análise das múltiplas correntes nos permite, assim, identificar quem são os atores e grupos de interesse que atuam no estabelecimento da agenda decisória governamental e nas especificações das alternativas de soluções para os problemas, que funcionam como incentivo para trazer o tema para o topo da agenda ou como obstáculo, reduzindo as chances de que determinado tema ou alternativa seja levado em consideração.

Feita essa breve apresentação sobre os pressupostos teóricos e metodológicos que embasam o método de análise de políticas públicas aqui proposto, avançaremos para a descrição detalhada da ferramenta, com a apresentação de cada um dos elementos do Quadro de Problemas, que visa permitir ao pesquisador analisar o contexto mais amplo do processo de formação e implementação de uma política pública, dividindo o foco entre as decisões já tomadas (que se materializam, muitas vezes, nos atos normativos que estruturam a ação governamental) e a identificação das características do arranjo jurídicoinstitucional, que permitem vislumbrar a movimentação dos atores na inclusão ou na retirada de temas da agenda política ou da arena de decisão.

\section{DESCRIÇÃO DA FERRAMENTA: OS ELEMENTOS DO QUADRO DE PROBLEMAS DE POLÍTICAS PÚBLICAS E A SOLUÇÃO HIPOTÉTICA}

Para viabilizar a realização de análises jurídico-institucionais de problemas públicos relacionados a programas de ação governamental não estruturados ou em processo de estruturação, apresentamos aqui a ferramenta Quadro de Problemas de Políticas Públicas, que procura sistematizar as relações entre variáveis relevantes da situação-problema, a partir de uma solução hipotética para ela. Essa solução hipotética orienta heuristicamente a coleta e organização de informações para o enfrentamento da situação-problema, com base na identificação dos seguintes elementos:

1) Situação-problema: situação fática que se pretende investigar como problema; problema público entendido coletivamente como relevante para ser tratado ou resolvido por meio de um programa de ação governamental; assunto relativo a uma política pública sobre o qual o pesquisador deseja se debruçar, associado a uma solução hipotética que diga respeito a uma política setorial, a determinado programa de ação governamental identificável, ou a uma ideia-diretriz de obra a se realizar em um grupo social ${ }^{15}$;

${ }^{15}$ Uma ideia-diretriz é, para Hauriou (2009), uma ideia de obra a se realizar em um grupo social, um plano de ação associado a metas e resultados a serem obtidos, a partir da ordenação do poder organizado, posto a serviço dessa ideia para a sua realização (BUCCI, 2013, p. 273). 
2) Diagnóstico situacional: caracterização do contexto político, econômico, social, cultural que permite verificar se o ambiente externo à arena institucional é propício ou não para decisões que determinem mudanças bruscas ou incrementais relativas à situação-problema (início de mandato presidencial ou de uma nova legislatura, cenário de crise econômica, catástrofes naturais; grau de politização e visibilidade da questão; histórico de tomadas de decisão ou de rejeição de soluções para a situação-problema);

3) Solução hipotética: idealização incipiente quanto a um instrumento, instituto ou procedimento, passível de ser regulado por meio de uma ou mais normas jurídicas, que presumivelmente seja capaz de solucionar a situação-problema identificada pelo analista; concepção inicial acerca de um programa de ação governamental; alternativa, proposta ou resolução que o pesquisador irá utilizar como parâmetro para analisar a situação-problema objeto de seu estudo (a solução pode ser expressa na forma de um projeto de lei, decreto, medida provisória, resolução, portaria, plano ou qualquer outro ato normativo que supostamente resolva, crie, organize, modifique ou extingua determinada ação governamental que possa solucionar o problema de política pública);

4) Contexto normativo: disposições normativas (constitucionais, legais e infralegais) que já regulam a política setorial na qual se insere a situaçãoproblema; normas que criam e especificam o funcionamento das competências que estariam mais diretamente ligadas à solução hipotética da situação-problema; sistemas normativos que se relacionam à situação-problema (decisões já tomadas e materializadas sobre a forma de normas que delimitam o contexto normativo no qual se insere a situação-problema);

5) Processo decisório: processo juridicamente regulado, estruturante da atuação do poder público, que deverá ser primordialmente acionado para a solução hipotética da situação-problema (processo eleitoral, processo legislativo, processo administrativo, processo orçamentário, processo judicial ${ }^{16}$ );

6) Etapa atual do processo decisório: estágio do processo decisório relativo à política pública no qual se insere a solução hipotética da situação-problema, que demanda uma decisão ou uma não-decisão (formação da agenda, formulação de alternativas, tomada de decisão, implementação, avaliação ${ }^{17}$ );

7) Arena institucional: espaço institucional no qual a controvérsia relativa à situação-problema e sua solução hipotética serão discutidas naquela etapa do processo decisório; desenho jurídico-institucional do ambiente de tomada de

16 Para uma discussão sobre os vários processos juridicamente disciplinados, que concretizam a ação governamental, ver Bucci (2013, p. 145-203).

${ }^{17}$ Identificamos aqui as etapas do processo decisório a partir do já mencionado modelo do ciclo de políticas públicas. Para uma discussão mais aprofundada sobre os estágios do ciclo, ver Secchi (2012). 
decisão (regras do jogo ${ }^{18}$, que digam respeito às regras de articulação e coordenação dos diferentes agentes, distribuição de competências e responsabilidades);

8) Protagonistas: agentes governamentais ou não-governamentais, indivíduos ou grupos de interesse favoráveis a determinada decisão sobre o problema, suas competências, atribuições, responsabilidades e grau de discricionariedade;

9) Antagonistas: agentes governamentais ou não-governamentais, indivíduos ou grupos de interesse contrários a determinada decisão sobre o problema, suas competências, atribuições, responsabilidades e grau de discricionariedade;

10) Decisores: responsáveis por tomar (ou não tomar) determinada decisão relativa à situação-problema; suas competências, atribuições, responsabilidades e grau de discricionariedade (no processo eleitoral, os candidatos e dirigentes dos partidos; no processo legislativo, os parlamentares, membros de comissões, líderes de bancadas; no processo administrativo, o ordenador de despesas, as chefias, os técnicos, os burocratas de nível de rua ${ }^{19}$, os gestores de contratos e parcerias; no processo judicial, os magistrados);

11) Recursos de barganha: táticas e estratégias utilizadas por protagonistas e antagonistas para influenciar os decisores a tomar ou não tomar determinada decisão (como recursos financeiros, capacidade de mobilização da opinião pública, capacidade de construção de coalizões ${ }^{20}$ );

Em síntese, cada um dos elementos descritos acima pretende identificar uma variável relevante para a descrição e compreensão de situações-problema relativas a programas de ação governamental.

\section{TESTE DE APLICAÇÃO DA FERRAMENTA: UMA ANÁLISE JURÍDICO- INSTITUCIONAL DO PROBLEMA DO HIPERENCARCERAMENTO NO BRASIL, A PARTIR DA ADPF 347}

Para verificar a pertinência da ferramenta proposta, utilizaremos o Quadro de Problemas de Políticas Públicas para descrever, de maneira bastante sucinta, o problema do hiperencarceramento no Brasil - o que, em tese, permitirá a análise jurídico-institucional daquilo que entendemos, aqui, como uma situaçãoproblema relativa à política prisional brasileira.

O hiperencarceramento é o termo comumente utilizado para caracterizar a atual situação do sistema prisional brasileiro, que observou um crescimento

\footnotetext{
${ }_{18}$ As regras do jogo se referem ao conjunto de normas institucionais que determinam a lógica do processo decisório, ou seja, as regras e os procedimentos a serem observados por atores políticos e grupos de interesse para a aprovação ou bloqueio de determinada decisão numa arena política específica (IMMERGUT, 1993).

${ }^{19}$ Os burocratas de nível de rua são os trabalhadores que interagem diretamente com cidadãos, no curso da implementação de uma política pública (LIPSKY, 1980; LOTTA, 2014).

${ }^{20}$ Para uma discussão mais aprofundada sobre táticas e estratégias de influência, ver Fisher (2015).
} 
vertiginoso da população carcerária nos últimos anos, acompanhado por um crescente déficit de vagas ${ }^{21}$. Com isso, o sistema apresenta, já há alguns anos, uma taxa de encarceramento superior à capacidade de vagas das unidades prisionais o que implica na superlotação das unidades e, consequentemente, em precariedade nas condições de cumprimento das penas de privação de liberdade e em privação de direitos e garantias constitucionais e legais aos indivíduos presos.

No último Levantamento Nacional de Informações Penitenciárias, realizado em 2016 pelo Departamento Penitenciário Nacional (BRASIL, 2017a) ${ }^{22}$, foi identificado um crescimento médio de $7,3 \%$ ao ano da população carcerária, passando de 232 mil pessoas em 2000 para 726 mil pessoas privadas de liberdade em 2016. No último ano do levantamento, registrou-se um déficit de 359.058 vagas no sistema ${ }^{23}$, o que representa nada menos que $49 \%$ do total de indivíduos encarcerados. Esses dados nos dão a dimensão da magnitude do problema público que está colocado para o Estado brasileiro.

Muitas medidas já foram propostas por diversos atores sociais, dentro e fora do Estado, para atacar o problema do hiperencarceramento. Mas destacamos aqui, pelo aspecto jurisdicional, a Arguição de Descumprimento de Preceito Fundamental (ADPF) ํo 347, de 2015 - uma ação junto ao Supremo Tribunal Federal (STF) que pretende o reconhecimento e a declaração, pelo Tribunal, do estado de coisas inconstitucional do sistema penitenciário brasileiro, com a consequente determinação de que o governo federal apresente à Côrte um Plano Nacional contendo propostas e metas para a superação dessa situação em todo o país. É a partir do conteúdo dessa ADPF que buscaremos empreender o teste de aplicação da ferramenta metodológica proposta por este artigo. A escolha se deve ao fato de que se trata de problema inequivocamente relevante, identificado pela ADPF 347 como tendo transcendido os limites da discricionariedade política para o encaminhamento de uma solução minimamente condizente com os valores

${ }^{21} \mathrm{O}$ déficit de vagas diz respeito ao número de indivíduos presos que excede a capacidade de vagas das unidades prisionais, ou seja, à diferença entre o número de vagas existentes no sistema penitenciário e o número de indivíduos efetivamente presos. O déficit é calculado a partir do número total de vagas das unidades prisionais, subtraído o número de presos nessas unidades.

${ }^{22} \mathrm{O}$ Departamento Penitenciário Nacional (DEPEN) é o órgão vinculado ao Ministério de Justiça e Segurança Pública, responsável pelo Sistema Penitenciário Federal.

${ }^{23}$ Considerando que a população carcerária total foi calculada em 726.275 presos no ano de 2016 (somando-se os condenados e os provisórios) e que as unidades prisionais estaduais dispunham, naquela data, de 367.217 vagas em todo o país, é possível verificar que a quantidade de vagas do sistema prisional suporta pouco mais da metade da atual população carcerária - ou, em outras palavras, que o Brasil encarcera quase duas vezes mais indivíduos do que seu sistema penitenciário tem efetivamente capacidade para suportar. Os dados do DEPEN informam que $78 \%$ dos estabelecimentos penais do país estão superlotados e que, do total da população carcerária, 292.450 pessoas (pouco mais de $40 \%$ do total de indivíduos encarcerados) são presos provisórios, ou seja, pessoas privadas de liberdade que sequer foram julgadas e ainda não receberam decisão condenatória. 
albergados pela ordem constitucional brasileira - daí o "estado de coisas inconstitucional".

Como veremos a seguir, o uso do Quadro de Problemas para descrever a questão do hiperencarceramento é, nesse texto, meramente ilustrativa sobre a aplicação do método aqui proposto. O tema é complexo e merece ser devidamente analisado por estudiosos que tenham maior familiaridade com o assunto. Feitas essas ressalvas acerca da limitação do escopo de aplicação da ferramenta a esse objeto nesse artigo, o uso do método nos permitiu identificar os seguintes elementos desse problema público:

1) Situação-problema: o fenômeno do hiperencarceramento vivenciado no Brasil a partir dos anos 1990, no qual se observa: i) um crescimento vertiginoso da população carcerária, com aumento do número de presos provisórios, e ii) situações degradantes e violações de direitos nos complexos penitenciários (celas superlotadas, ausência de assistência material, de segurança, de alimentação adequada, de acesso à justiça, à educação, à assistência médica integral, ao trabalho digno e remunerado, além de tortura e maus tratos) ${ }^{24}$.

2) Diagnóstico situacional: o contexto político, econômico, social e cultural no qual se insere a discussão sobre o problema do hiperencarceramento pode ser identificado da seguinte forma: i) a partir de 2002, a Corte Interamericana de Direitos Humanos passou a expedir resoluções, condenando o Estado brasileiro a cumprir medidas para garantir a erradicação das situações de risco e providenciar a proteção à vida e à integridade pessoal, psíquica e moral de pessoas privadas de liberdade em várias penitenciárias do país; ii) em 2008, foi publicado o relatório final da CPI do Sistema Carcerário na Câmara dos Deputados ${ }^{25}$, que evidenciava o tratamento degradante dado aos presos no sistema penitenciário brasileiro; iii) a partir de 2008, o CNJ passou a realizar mutirões carcerários em presídios de todas as unidades da federação, e a divulgar relatórios com um diagnóstico da situação prisional do país; iv) em 2013, foi inaugurado em Minas Gerais o primeiro complexo penitenciário brasileiro construído e administrado pela iniciativa privada, por meio de uma parceria público-privada; v) em maio de 2015, foi protocolada a ADPF 347 no Supremo Tribunal Federal; vi) em setembro de 2015, o Tribunal julgou a medida cautelar da ADPF 347, deferindo a liminar em parte, determinando a realização de audiências de custódia por juízes e tribunais; determinando a liberação do saldo acumulado do Fundo Penitenciário Nacional pela União, abstendo-se de realizar novos contingenciamentos e determinando à União e aos Estados o encaminhamento, ao Tribunal, de informações sobre a

\footnotetext{
${ }^{24}$ As informações aqui referidas foram retiradas exclusivamente da petição inicial da ADPF 347, a título de ilustração da utilização da ferramenta.

${ }^{25} \mathrm{O}$ documento encontra-se disponível em: <http://bd.camara.gov.br/bd/handle/bdcamara/2701>.
} 
situação prisional; vii) uma auditoria do Tribunal de Contas da União ${ }^{26}$ sobre o sistema prisional brasileiro em 2017 identificou que a) o excesso populacional nas unidades prisionais prejudica a atuação do Estado na garantia da ordem e da segurança dos indivíduos encarcerados e favorece a atuação de faç̧ões criminosas dentro desses estabelecimentos, b) que as unidades da federação não possuem sistemas para acompanhamento da execução das penas, c) que todos os estados apresentam déficit de vagas em suas unidades prisionais, e d) que os gestores desconhecem o custo mensal do preso por estabelecimento penal, o que dificulta o gerenciamento de recursos e implica uma baixa eficiência da administração dos estabelecimentos prisionais; viii) em 2019, a morte de 57 presos em um presídio em Altamira (PA), em decorrência de um conflito entre duas facções criminosas pelo controle da unidade prisional, reascendeu o debate sobre a situação dos presídios no país, abrindo uma janela de oportunidade para o acoplamento dos fluxos dos problemas, soluções e política, de que depende a tomada de decisão sobre o problema do hiperencarceramento.

3) Solução hipotética: na petição inicial da ADPF 34727, pretende-se que o Supremo Tribunal Federal declare o estado de coisas inconstitucional do sistema penitenciário brasileiro, e que determine ao Governo Federal que elabore um "Plano Nacional", contendo propostas e metas específicas para a superação das graves violações aos direitos fundamentais dos presos em todo o país, especialmente no que toca à i) redução da superlotação dos presídios; ii) contenção e reversão do processo de hiperencarceramento existente no país; iii) diminuição do número de presos provisórios; iv) adequação das instalações e alojamentos dos estabelecimentos prisionais aos parâmetros normativos vigentes, no que tange a aspectos como espaço mínimo, lotação máxima, salubridade e condições de higiene, conforto e segurança; v) efetiva separação dos detentos de acordo com critérios como sexo, idade, situação processual e natureza do delito; vi) garantia de assistência material, de segurança, de alimentação adequada, de acesso à justiça, à educação, à assistência médica integral e ao trabalho digno e remunerado para os presos; vii) contratação e capacitação de pessoal para as instituições prisionais; viii) eliminação de tortura, de maus tratos e de aplicação de penalidades sem o devido processo legal nos estabelecimentos prisionais; ix) adoção de medidas visando a propiciar o tratamento adequado para grupos vulneráveis nas prisões, como mulheres e população LGBT. O Plano Nacional, segundo o pedido da inicial, deve conter, também, a previsão dos recursos necessários para a implementação das suas propostas, bem como a definição de

\footnotetext{
${ }^{26}$ No ano de 2017, foi realizada uma auditoria sobre o sistema prisional, coordenada pelo TCU, abrangendo o Distrito Federal e mais 17 estados. O relatório dessa auditoria pode ser acessado no Acórdão 2643/2017, do Processo TC 003.673/2017-0, ver Brasil (2017b).

27 As peças do processo da ADPF 347 podem ser acessadas no site do STF, em: $<$ http://redir.stf.jus.br/estfvisualizadorpub/jsp/consultarprocessoeletronico/ConsultarProcessoEle tronico.jsf?seqobjetoincidente=4783560>. Acesso em: 14 out. 2019.
} 
um cronograma para a efetivação das medidas de incumbência da União Federal e de suas entidades. Segundo o pedido da ADPF, após a homologação do Plano Nacional, deverá o STF determinar ao governo de cada Estado e do Distrito Federal que formule e apresente um plano estadual ou distrital, que se harmonize com o Plano Nacional homologado, e que contenha metas e propostas específicas para a superação do estado de coisas inconstitucional na respectiva unidade federativa. Caberá ao STF, por fim, deliberar sobre cada plano estadual e distrital, para homologá-los, além de monitorar a implementação do Plano Nacional e dos planos estaduais e distrital, com o auxílio do Departamento de Monitoramento e Fiscalização do Sistema Carcerário e do Sistema de Execução de Medidas Socioeducativas do Conselho Nacional de Justiça.

4) Contexto normativo: a política prisional brasileira, na qual se insere o problema do hiperencarceramento, está regulada pelas seguintes disposições normativas:

4.1) Constituição Federal, que consagra direitos e garantias para os indivíduos presos: assegura o princípio da dignidade da pessoa humana (art. 1ํㅡㄴ III), proíbe a tortura e o tratamento desumano ou degradante (art. 5ㅇ, III), veda as sanções cruéis (art. 5o, XLVII, " $\mathrm{e}^{\circ}$ ), impõe o cumprimento da pena em estabelecimentos distintos, de acordo com a natureza do delito, a idade e sexo do apenado (art. 5o, XLVIII), assegura aos presos o respeito à integridade física e moral (art. $5^{\circ}$, XLIX), e prevê a presunção de inocência (art. 5\%, LVII).

4.2) Lei de Execução Penal (LEP), que: i) contém regras para a individualização da pena; ii) determina a obrigatoriedade do Estado em fornecer ao preso assistência material, à saúde, jurídica, educacional, social, religiosa e trabalho; iii) dispõe sobre faltas disciplinares, sanções e recompensas; iv) determina as competências do Conselho Nacional de Política Criminal e Penitenciária do juízo de execução, do Ministério Público, do Conselho e dos Departamentos Penitenciários; v) prevê regras de funcionamento para os estabelecimentos penais; vi) prevê regras para o cumprimento dos diferentes tipos de penas e vii) prevê regras para a progressão de regime.

4.3) Resoluções do CNJ, como a Resolução no 113/2010 que dispõe sobre o procedimento relativo à execução de pena privativa de liberdade e de medida de segurança.

4.4) Tratados internacionais sobre direitos humanos ratificados pelo país, como i) o Pacto dos Direitos Civis e Políticos, ii) a Convenção contra a Tortura e outros Tratamentos e Penas Cruéis, Desumanos e Degradantes e iii) a Convenção Interamericana de Direitos Humanos.

4.5) Documentos internacionais atinentes a aspectos como as condições, tamanho, uso, capacidade, salubridade, lotação e ocupação de unidades prisionais e celas, como i) as "Regras Mínimas para o Tratamento de Prisioneiros" da ONU e 
ii) os "Princípios e Boas Práticas para a Proteção das Pessoas Privadas de Liberdade nas Américas", da Comissão Interamericana de Direitos Humanos ${ }^{28}$.

5) Processo decisório: o problema do hiperencarceramento é objeto de um processo judicial, uma ADPF em tramitação no STF, que objetiva o reconhecimento do estado de coisas inconstitucional do sistema penitenciário brasileiro e propõe a adoção de providências tendentes a sanar as lesões a preceitos fundamentais da CF/88, decorrentes de condutas dos Poderes Públicos no tratamento da questão prisional, com a elaboração de planos federal, estaduais e distrital que contenham propostas e metas específicas para a superação das graves violações aos direitos fundamentais dos presos em todo o país.

A existência de uma ADPF pode levar o pesquisador a supor que o processo decisório no qual está inserido o problema do hiperencarceramento seja aquele processo judicial em curso no STF. No entanto, um dos pedidos da ação (para que se determine ao Governo Federal a elaboração de um Plano Nacional visando à superação do estado de coisas inconstitucional) nos orienta para o fato de que a competência para a tomada de decisão sobre a questão da política prisional no Brasil não é propriamente do Poder Judiciário, mas sim do Poder Executivo, principal protagonista da iniciativa para a existência, conformação e adequação de uma política pública ${ }^{29}$.

Nesse sentido, identifica-se que o processo decisório sobre o problema do hiperencarceramento não se encontra, precisamente, no processo judicial, mas sim em outros processos, no âmbito do Poder Executivo. Uma vez que a LEP determina ser atribuição do Departamento Penitenciário Nacional (órgão executivo da Política Penitenciária Nacional, subordinado ao Ministério da Justiça) colaborar com as Unidades Federativas na implantação de estabelecimentos penais ${ }^{30}$, seria mais acurado identificar a situação-problema como inserida em processos decisórios centrados no âmbito dos Poderes Executivos dos estados (quais sejam, o processo administrativo e/ou o processo orçamentário). A complexidade do problema é bastante agravada pela multiplicidade de pólos de competência, envolvendo Estados e União.

6) Etapa do processo decisório: considerando a existência de inúmeros indicadores que demonstram a magnitude do problema do hiperencarceramento no Brasil (muitos deles descritos na petição inicial da ADPF 347 e outros apontados por recente auditoria do Tribunal de Contas da União sobre o sistema prisional, como o conflito de facções criminosas no interior das unidades

\footnotetext{
${ }^{28}$ As normas aqui elencadas são meramente exemplificativas e não há pretensão, nesse artigo, de se mapear todas as disposições normativas aplicáveis à política prisional brasileira.

${ }^{29}$ Para uma discussão sobre a tensão no exercício de competências próprias do Poder Judiciário e do Poder Executivo na conformação das políticas públicas, ver Bucci (2017).

30 A execução penal, apesar de ser de competência federal, fica majoritariamente a cargo das unidades federativas, já que a maior parte dos indivíduos são processados, julgados e custodiados pelas autoridades locais.
} 
prisionais, que tem implicado num número crescente de assassinatos de presos custodiados pelo Estado dentro das unidades); e considerando a existência de um grande número de alternativas, propostas por pesquisadores e burocratas para solucioná-lo (como a construção de novas unidades prisionais pelo Estado, a utilização do instituto das parcerias-público-privadas para a edificação e administração de novos presídios; a modificação dos procedimentos e rotinas das unidades prisionais, para a adequação do cumprimento das penas às disposições legais; a realização de mutirões carcerários, para a definição dos casos dos presos provisórios; o abolicionismo penal e aplicação das penas alternativas, para a redução do volume de indivíduos presos por determinados tipos penais, dentre outras), nossa hipótese é de que o problema do hiperencarceramento integra a agenda pública, com alternativas formuladas, mas a questão encontra-se estancada na etapa de tomada de decisão.

Trata-se de uma situação emblemática que pode ser analisada a partir do modelo das múltiplas correntes, pois se verifica que não tem ocorrido um acoplamento entre o fluxo do problema, da solução e da política, para que uma determinada decisão seja efetivamente tomada, seja em nível nacional, estadual ou distrital, para tratar da questão em tela.

7) Arena institucional: considerando que o problema esteja estancado na etapa de tomada de decisão, de um processo decisório administrativo e/ou orçamentário, no âmbito do Poder Executivo, identificamos que o ambiente de tomada de decisão para esse problema deve ser o Departamento Penitenciário Nacional e os Departamentos Penitenciários locais (cujas atribuições estão descritas na Lei de Execução Penal). Importante ressaltar que o Ministério da Justiça identificou que apenas 6 (seis) estados brasileiros possuem órgão gestor que cuida exclusivamente da Administração Penitenciária, sendo que nos demais estados, não há uma Secretaria própria para administrar esta política (BRASIL, 2016, p. 169). Nesse sentido, para uma compreensão mais acurada do desenho jurídico-institucional do ambiente de tomada de decisão nos estados, seria necessário identificar quais são os órgãos gestores locais e suas atribuições específicas, a partir das disposições normativas que regem o funcionamento dessas instituições ${ }^{31}$.

8) Protagonistas: podemos identificar como sujeitos interessados na tomada de decisão sobre o problema do hiperencarceramento, os chefes do Poder Executivo dos estados; os dirigentes e servidores dos órgãos gestores da política prisional nos estados; os dirigentes e servidores das unidades prisionais; os sindicatos dos servidores das unidades prisionais; as organizações da sociedade civil que atuam para a defesa dos direitos da população carcerária; os indivíduos presos, suas lideranças e organizações criminosas presentes nos presídios; e as empresas

${ }^{31}$ Esse detalhamento não será empreendido nesse trabalho, uma vez que a aplicação do Quadro de Problemas à questão do hiperencarceramento é, aqui, meramente ilustrativa da utilização da ferramenta. 
eventualmente interessadas na celebração de parceria-público-privada para a gestão das unidades prisionais. Para uma leitura mais completa do problema, as competências, atribuições e responsabilidades de cada um desses agentes devem ser verificadas em cada unidade federativa, a partir das normas que regem as carreiras, as atribuições dos agentes públicos e as relações público-privadas entre os atores mencionados.

9) Antagonistas: considerando que a solução hipotética apresentada na ADPF 347 propõe a elaboração de planos nacionais, estaduais e distritais que contenham propostas e metas específicas para o enfrentamento do problema do hiperencarceramento e reconhecendo que o conteúdo substantivo desses planos é de competência do Governo Federal e de órgãos dos Poderes Executivos dos Estados e do Distrito Federal, fica evidente que a alternativa heurística até aqui apresentada para o solucionamento do problema não nos permite avançar para a identificação de todos os elementos do Quadro de Problemas. Nesse sentido, verifica-se a necessidade de consideração de outra solução hipotética, de conteúdo substantivo mais preciso, que nos permita avançar na utilização da ferramenta, uma vez que a ausência de um viés específico de decisão inviabiliza a identificação de quais agentes apresentam posição favorável ou contrária a determinada decisão. Mas supondo, por exemplo, que um viés de decisão possível (uma nova solução hipotética) em um determinado estado fosse a adoção do instituto das parcerias público-privadas para a construção e administração de novas unidades prisionais, capazes de dar conta do déficit de vagas do sistema, garantindo melhores condições de alojamento dos indivíduos presos, seria possível posicionar o chefe do Poder Executivo, os dirigentes dos órgãos gestores da política prisional e as empresas interessadas na celebração da parceria como protagonistas; enquanto que os servidores das unidades prisionais, sindicatos da categoria e, eventualmente os indivíduos presos, suas lideranças e organizações criminosas como antagonistas ${ }^{32}$.

10) Decisores: os responsáveis por tomar a decisão de adotar (ou não) o instituto das parcerias público-privadas para a construção e administração de novas unidades prisionais seriam os chefes do Poderes Executivos dos estados; dirigentes e servidores dos órgãos gestores da política prisional nos estados. As competências e responsabilidades de cada um desses agentes devem ser verificadas em cada unidade federativa, a partir da análise das disposições normativas que determinam as atribuições e o grau de discricionariedade de cada um desses atores.

11) Recursos de barganha: os sindicatos dos servidores das unidades prisionais e as organizações da sociedade civil que atuam para a defesa dos direitos da população carcerária possuem grande capacidade de mobilização da opinião

32 Importante destacar que, adotada a nova solução hipotética, caberia ao analista rever a identificação dos elementos do quadro. 
pública; as organizações criminosas exercem grande pressão sobre os decisores, especialmente pelo controle que detém sobre o funcionamento das unidades prisionais; as empresas eventualmente interessadas na celebração de parceriapúblico-privada para a gestão das unidades prisionais dispõem principalmente de recursos financeiros. As estratégias utilizadas pelos protagonistas e antagonistas para influenciar os decisores a tomar ou não tomar determinada decisão devem ser examinadas pelo pesquisador a partir das disposições normativas que determinam a arena institucional na qual a controvérsia será discutida, no sentido de verificar a admissibilidade e/ou eventuais ilegalidades no uso de determinadas táticas de influência - o que pode impactar de maneira decisiva na validade da norma e na legitimidade do procedimento decorrente da decisão tomada.

É evidente que os elementos acima descritos, nessa abordagem preliminar sobre a questão do hiperencarceramento, não são capazes de abarcar todos os detalhes do arranjo jurídico-institucional que envolve o problema da política prisional. E, definitivamente, não era esse o intuito desse estudo. A descrição realizada teve a estrita finalidade de examinar a viabilidade da ferramenta aqui proposta (Quadro de Problemas de Políticas Públicas), e demonstrar como esse método estruturado pode auxiliar o pesquisador a identificar os elementos mais relevantes para a análise jurídica de um problema de política pública.

\section{CONSIDERAÇÕES FINAIS}

Esse artigo procurou apresentar e descrever um novo método de sistematização de informações, o Quadro de Problemas de Políticas Públicas, que se propõe a viabilizar a análise jurídico-institucional de situações-problema relativas aos programas de ação governamental.

Essa ferramenta visa possibilitar o estudo jurídico de problemas públicos relacionados a políticas públicas pouco estruturadas ou em processo de estruturação, para os quais o uso do Quadro de Referência de uma Política Pública (BUCCI, 2015) se mostra insuficiente. Nesse sentido, o Quadro de Problemas se apresenta como um instrumento complementar ao Quadro de Referência, capaz de auxiliar o trabalho do pesquisador que queira examinar, de maneira conjunta, os elementos jurídicos e os elementos políticos de um problema público a partir da abordagem Direito e Políticas Públicas.

Esse método apresenta uma vantagem analítica, no sentido de amparar o pesquisador a vislumbrar os agentes e os arranjos jurídico-institucionais que estão por trás do processo de tomada de decisão, seja no processo legislativo (que antecede a aprovação, por exemplo, de uma lei que crie determinado programa de ação governamental), seja no processo administrativo em sentido amplo (na determinação de regras e procedimentos relativos à implementação de determinado aspectos de um programa de ação governamental), seja no processo judicial (que pode determinar à administração que a lógica previamente 
estabelecida para determinada política seja alterada numa situação específica, em virtude de uma decisão judicial individualizada ${ }^{33}$ ).

A utilização dessa ferramenta pretende ajudar a elucidar os aspectos políticos do problema, em sua interface com os aspectos jurídicos, na medida em que procura mapear o ambiente de tomada de decisão acerca de um problema público - os atores, instituições, regras e procedimentos a serem observados pelos grupos de interesse e decisores na aprovação dos dispositivos normativos que irão, posteriormente, estruturar a ação governamental para o tratamento da situaçãoproblema em análise.

O método, ao fazer referência a modelos consagrados de análise de políticas públicas, à linguagem, a termos e conceitos de outras áreas do conhecimento, pretende estabelecer uma interface com outras disciplinas, viabilizando maior diálogo entre os pesquisadores do campo de públicas.

O propósito de combinar os pressupostos teóricos e metodológicos do campo do Direito com aqueles mais característicos de estudos no campo da Ciência Política, por exemplo, é estreitar o intercâmbio disciplinar, de modo a colaborar com a vocação interdisciplinar do campo de análise de políticas públicas permitindo aos estudiosos do Direito o contato com teorias e métodos característicos da Ciência Política e possibilitando aos cientistas políticos e estudiosos de outras áreas que vislumbrem a relevância do elemento jurídico para a compreensão dos arranjos institucionais nos quais operam os atores sociais para o planejamento e execução dos programas de ação governamental.

Esperamos que essa ferramenta permita o avanço das análises jurídicoinstitucionais das políticas públicas e se revele profícua para instrumentalizar a ação prospectiva, no sentido do aperfeiçoamento dos arranjos institucionais e da ação governamental a partir de uma perspectiva jurídica, tornando-os mais eficazes (para que atinjam resultados em menor tempo, com menor custo e mais qualidade), legítimos (para que se fomente a participação dos atores sociais implicados) e efetivos (para que se realizem os objetivos legais e os direitos constitucionais que os embasam) (BUCCI; COUTINHO, 2017).

\section{REFERÊNCIAS}

BACHRACH, Peter; BARATZ, Morton S. Decisions and Nondecisions: An Analytical Framework. The American Political Science Review, v. 57, n. 3, 1963, p. 632-642.

${ }_{33}$ Para uma discussão sobre os efeitos do controle judicial de políticas públicas na política da saúde, ver Bucci (2017). 
BACHRACH, Peter; BARATZ, Morton S. Duas Faces do Poder. Revista de Sociologia e Política, v. 19, n. 40, 2011.

BRASIL. Ministério da Justiça. Modelo de Gestão para a Política Prisional. Brasília, 2016. Disponível em: <http://www.justica.gov.br/central-deconteudo/politica-penal/modelo-de-gestao_documento-final.pdf $>$. Acesso em: 12 ago. 2019.

BRASIL. Ministério da Justiça e Segurança Pública. Departamento Penitenciário Nacional. Levantamento Nacional de Informações Penitenciárias: INFOPEN. Brasília, DF: Ministério da Justiça e Segurança Pública, 2017a. Disponível em: $<$ http://depen.gov.br/DEPEN/noticias-1/noticias/infopen-levantamento-nacionalde-informacoes-penitenciarias-2016/relatorio_2016_22111.pdf>. Acesso em: 12 ago. 2019.

BRASIL. Supremo Tribunal Federal. ADPF 347/DF. Relator: Min. Marco Aurélio. Brasília, 2015. Disponível em: <https://www.conjur.com.br/dl/psol-stf-intervenhasistema-carcerario.pdf>. Acesso em: 12 ago. 2019.

BRASIL. Tribunal de Contas da União. Auditoria Coordenada sobre o Sistema Prisional. Relatora: Ministra Ana Arraes. Brasília, 2017b. Processo TC 003.673/2017-0. Acórdão TCE Plenário nº 2643/2017. Disponível em: $<$ https://portal.tcu.gov.br/imprensa/noticias/realidade-prisional-auditoria-mostraque-o-custo-mensal-do-preso-e-desconhecido-em-varios-estados.htm>. Acesso em 12 ago 2019.

BUCCI, Maria Paula Dallari; COUTINHO, Diogo. Arranjos jurídico-institucionais da política de inovação tecnológica. Uma análise baseada na abordagem de Direito e Políticas Públicas. In: COUTINHO, Diogo R.; FOSS, Maria Carolina; MOUALLEM, Pedro Salomon B. (orgs.). Inovação no Brasil: avanços e desafios jurídicos e institucionais. São Paulo: Blucher, 2017.

BUCCI, Maria Paula Dallari. Contribuição para a redução da judicialização da saúde. Uma estratégia jurídico-institucional baseada na abordagem de Direito e Políticas Públicas. In: BUCCI, Maria Paula Dallari; DUARTE, Clarice Seixas (coords.). Judicialização da saúde: a visão do Poder Executivo. São Paulo: Saraiva, 2017. 
BUCCI, Maria Paula Dallari. Fundamentos para uma Teoria Jurídica das Políticas Públicas. São Paulo: Saraiva, 2013.

BUCCI, Maria Paula Dallari. O conceito de política pública em direito. In: BUCCI, Maria Paula Dallari (org.). Políticas Públicas. Reflexões sobre o Conceito Jurídico. São Paulo: Saraiva, 2006.

BUCCI, Maria Paula Dallari. Quadro de Referência de uma Política Pública: primeiras linhas de uma visão jurídico-institucional. In: SMANIO, Gianpaolo Poggio; BERTOLIN, Patrícia Tuma; BRASIL, Patrícia Cristina (org.). O Direito na Fronteira das Políticas Públicas. São Paulo: Páginas e Letras Editora e Gráfica, 2015.

BUCCI, Maria Paula Dallari. Direito e políticas públicas: método e aplicações. Revista Estudos Institucionais, v. 5, n. 3, 2019.

COUTINHO, Diogo, O Direito nas Políticas Públicas. In: MARQUES, Eduardo; PIMENTA DE FARIA, Carlos Aurélio (eds.). Política Pública como Campo Multidisciplinar. São Paulo: Ed. UNESP, 2013.

FISHER, Stacy. Strategic influence in legislative lobbying: context, targets, and tactics. New York: Palgrave Macmillan, 2015.

HAURIOU, Maurice. A Teoria da Instituição e da Fundação. Porto Alegre: Sergio Antonio Fabris Editor, 2009. Tradução de José Ignacio Coelho Mendes Neto, p. 1154.

IMMERGUT, Ellen. As regras do jogo: a lógica da política de saúde na França, na Suíça e na Suécia. Revista Brasileira de Ciências Sociais, n. 30, 1993.

KINGDON, John W. Agendas, Alternatives and Public Policies. 2 ed. New York: Harper Collins College Publishers, 1995.

KINGDON, John W. Juntando as Coisas. Tradução: Paulo César Nascimento. In: SARAVIA, Enrique; FERRAREZI, Elisabete (org). Políticas Públicas: Coletânea Volume 1. Brasília: ENAP, 2006.

LIPSKY, Michael. Street-level bureaucracy: dilemmas of the individual in public services. Nova York: Russel Sage Foundation, 1980. 
LOTTA, Gabriela. Agentes de implementação: uma forma de análise de políticas públicas. Cadernos Gestão Pública e Cidadania, v. 19, n. 65, 2014.

MANCUSO, Wagner Pralon; GOZETTO, Andréa Cristina Oliveira. Lobby e Políticas Públicas. Rio de Janeiro: FGV Editora, 2018.

MARQUES, Eduardo C. L. As políticas públicas na Ciência Política. In: MARQUES, Eduardo; PIMENTA DE FARIA, Carlos Aurélio (org.). A Política Pública como Campo Multidisciplinar. São Paulo: Editora UNESP/Editora Fiocruz, 2013.

MORAND, Charles-Albert. Le droit neo-moderne des politiques publiques. Paris: LGDJ, 1999.

OSTROM, Elinor. Institutional rational choice: an assessment of the institutional analysis and development framework. In: SABATIER, Paul A (org.). Theories of the policy process. Colorado: Westview Press, 2007.

SABATIER, Paul A. The need for better theories. In: SABATIER, Paul A.; WEIBLE, Christopher M. (eds.). Theories of the Policy Process. Colorado: Westview Press, 2007.

SECCHI, Leonardo. Políticas Públicas. Conceitos, Esquemas de Análise, Casos Práticos. São Paulo: Cengage Learning, 2012. 